\title{
On the Role of Career Planning in College Students' Employment Guidance
}

\author{
Bo GAO \\ College of Mathematics and Statistics, Yu Lin University \\ Yu Lin 719000, China
}

\begin{abstract}
With the development of the popularization of higher education, the employment of university students has caused extensive social concerning. This paper discusses the need to strengthen the career planning education in the college employment guidance, and focusing on employment is not a graduation issue, but the systematic career planning education throughout the university is an important way to enhance the employ ability of university students.
\end{abstract}

Keywords-Career planning education; Employment guidance; Function

\section{INTRODUCTION}

The university student's employment has been an issue of public concern in the process of higher education expansion in China. On the one hand, generally college students are lack of work experience, with high expectation of employment and unreasonable knowledge structure, on the other hand, their career preparation is insufficient and career orientation is unscientific, which lead to frequent rebuff in career selection. According to the statistics of large-scale talent exchanges held in major cities in China, most students participate in the talent Exchange fair with the feeling of "go to the market", they have no target, no preparation, all by chance, generally the success rate of the exchanges is $30 \%$. The lack of career preparation affects and restricts the success rate of market allocation to a certain extent. Therefore, how to strengthen college students ' career planning education, help students discover and cultivate their potentials and creativity, and fundamentally improve the employ ability of graduates, which has become a practical task for each university's employment guidance work.

\section{CURRENT PROBLEM IN COLLEGES AND UNIVERSITIES' EMPLOYMENT GUIDANCE}

The purpose of university employment guidance is to guide students to obtain a kind of employment ability, the survival ability facing the society, which is not only limited to provide the necessary help for the graduates 'employment, but also to provide the students with the ability of lifelong employment, and make them have the ability to manage their career, and constantly seek more suitable career. But the issues on current employment guidance work have affected the purpose of this work.

\section{A. Employment guidance focuses on the placement of} graduates, emphasizing the first employment rate

The current employment guidance for college students stays in the placement work for students, emphasizing the first employment rate. On the one hand, the employers are lack of "talents needed", on the other hand, the phenomenon of unemployed students is prominent. The phenomenon of "looting industry", there are some widely existing phenomena in the job market, such as "blind career choice", "high rate of default ","high cost of employment" and so on [1].

\section{B. College students lack of self-awareness in job-seeking, short of employment subjectivity}

College students lack of self-awareness in job-seeking, short of employment subjectivity, their subjective consciousness is weak, which is reflected in three parts: firstly, students rely on school teachers and parents in the process of job-seeking, they have not well prepared for their job and their initiative is not enough; secondly, students lack of career planning awareness and have no objective rational understanding of oneself, so that their objective is vague and lack of clear strategic idea in job-hunting; thirdly, they lack of autonomy in job-seeking, especially the lack of entrepreneurial awareness, high entrepreneurial expectations and insufficient entrepreneurial capacity.

\section{Without highly scientific and professional level, university Students 'employment guidance have not run throughout the whole university education}

The model of current college students' employment guidance provided employment information for the platform, aimed at realizing employment placement, with employment policy and skills as the main guide content, which has not reached a highly scientific and professional level.

Most of teachers in class are without solid foundation and training or lack of theoretical basis; or teachers themselves do not understand the actual situation of the employment, they can only talk about empty theory; and they lack of planning the whole career development for college students.

The aim of a student receiving higher education is to obtain higher employ ability and more employment opportunities. The purpose of the college career planning education is to make the university students with initiatives to establish the professional goals under the guidance of the relevant departments and experts when they enter the school, and to arrange their own 
learning and training accordingly. How to choose careers, how to find their own career positioning and how to achieve a career attract a lot of college students' attention and consideration when they entered the University.

\section{THE ROLE OF CAREER PLANNING IN EXPANDING EMPLOY ABILITY OF COLLEGE STUDENTS}

Successful career planning will enable college students to position their careers scientifically, correctly understand the social competition and their value in society, so that they can solve the employment problem more smoothly, show their talents and promote personal progress and social development.

\section{A. The implication and content of career planning}

Career planning, also called career design, refers that a person make a plan for his own future career development process, specifically refers to the individual combination of their own situation, the opportunity and constraints, determination of their career direction, career objectives, the choice of career path, determination of study plan, training plans and development plans, in a word, career planning is to define action plan for achieving career goals [2].

Career planning guidance, in general terms, is to help students answer three questions: "Who am I?" Where do I go? "How do I get there?" It is a systematic work to answer these questions, which involve all the functional departments and teaching progress of the school. A systematic career-related curriculum with full-time tutors is required. College students are at the stage of the exploration of individual career; the career choice at this stage is of great significance for college students' future career development.

\section{B. The relationship between career planning and employ ability}

Employ ability is the ability to obtain and maintain work, including learning ability, practical ability, professional ability, innovation ability, thinking ability, interviewing ability, psychological quality and so on. Employ ability can directly influence whether students can grasp the opportunity to find ideal jobs, enter the role as soon as possible when they get a job and competent this job. Therefore, the most critical factors in how to improve the employ ability of students are effective career guidance education and career planning with personal characteristics.

College students ' career planning is the first step towards success, which can help them to realize their goals earlier, and design a reasonable and feasible career development direction according to their personal strengths, weaknesses, interests and environmental factors. Falling down on the employment guidance will affect the student's employment quality and the success degree of graduate profession development.

In fact, students' good employability is unlikely to be improved overnight in career guiding before graduation. The problems of college students in choosing a career are difficult to be solved during the process of job hunting, which is permeated with the training of professional interest and the long practice of career education. The process of students' employment, previous studies, career and after career is a whole, which need to be guided systematically, lack of any one of the process will affect the career development throughout students' life.

\section{Effect of career planning on the improvement of employ ability of college students}

In western countries, employment guidance begins in primary school, the initial phase of career education is in the high school, at the university stage, the school set up a career planning counseling and counseling center institutions, and all school combine students' campus life and career development in education and management to help students prepare for personal career planning with necessary conditions [3]. This education model has enabled the development of human resources in these countries and has played a key role in the development of national economy by providing talents for their scientific and technological progress and innovation.

The successful experience of career planning education in Western countries tells us that employment guidance is an overall guidance based on the core element of career education, which combines the students ' career desire with the process of college education and social development. At present, the low awareness of career planning in college student is obviously not conducive to college students ' employment. At the same time, most universities pay more attention to the employment rate, and the individuality and specialty of college students attach less importance to in employment.

Professor $\mathrm{M} \cdot \mathrm{L} \cdot G o d e s m i d e$ said: "Apart from the responsibility of the university to impart a wide range of scientific and cultural knowledge to students, one of its missions is to provide the necessary preparation for the employment of its graduates. [4]" University is to become the intermediate medium that "college students are from theoretical knowledge learning to career life." There are many factors that determine the success of employment, but the most important factors are knowledge, ability and skills, that is to say, college students should have a reasonable knowledge structure to adapt to social development and professional requirements, and have practical application ability to satisfy the needs of society.

\section{THE IMPLEMENTATION OF CAREER PLANNING EDUCATION}

Career planning education should run through the whole university education, aiming at different grades, highlighting the key points, implementing them step by step, and gradually forming a comparatively perfect career guidance system.

\section{A. Constructing systematic college students ' career education system and improving the practicability of employment guidance}

The university's employment guidance is a gradual process, the first year in university, students mainly accept the professional ideal and the career view that is the foundation and future of the graduate job-hunting; the second year is to cultivate and prepare the basic employment ability, which is the continuation of the career ideal education; the third and the fourth year is to take the employment practice education, which is the training stage of the employment education. 
So in the stage of university career planning education, firstly it is necessary to consider the construction of rational knowledge structure, the accumulation of knowledge is the foundation and necessary condition for talents; secondly, we should focus on improving the decision-making ability, creative ability, social ability, practical operation ability, organization and management ability, Self-development and lifelong learning ability, psychological adjustment ability and adaptability to cultivate the practical ability of professional needs; thirdly, students should participate in beneficial vocational training, be engaged in some social part-time work, learn more about occupation, master professional skills, and correctly guide their career development [5].

\section{B. Perfect the socialized service organization of college students ' career education}

The core of vocational education service institutions in colleges and universities is the school, followed by society and enterprise. These institutions could not just provide a dizzying job-placement message and hold a temporary career-guidance session. The university should combine with the society to explore the open talent training mode, set up the outside practice and practice base for the students, organize the students to carry out the employment practice activities, so that the university students can gain the experience, position themselves objectively and accurately and shorten the adaptation period to the society. At the same time, let students know their knowledge ability and social gap, adjust and supplement in time, so that their professional knowledge and social development, their potential ability and future career can make common development.

The establishment of social service institutions and the provision of counseling and evaluation services is the common responsibility of universities and society. These information services include employment information services, policy advisory services, recruitment services, processing services, etc. psychological counseling career direction counseling, employment channel counseling, and individual personalized counseling should also be provided timely for college students.

\section{Training a high-quality faculty in professional career planning education}

Career planning education is a highly theoretical and practical course, with the development of society, the demand for theory and technology is more than before, which requires the school to cultivate a professional and expert team, to provide students with the needs of personality development career planning. Teachers should analyze the current employment situation objectively according to the social economic situation and the law of personal development, and guide students to make scientific and reasonable career development goals [6].

Therefore, college students' employment is the combination of right scientific career choice and responsible career ideal planning and implementation; employment guidance is not only to guide graduates how to find a job, but also to help students find and cultivate their potential and creativity when students make career choices. Therefore, colleges and universities should strengthen the education of college students ' career planning in the current employment guidance work. So that college students can study more actively according to their interests and the judgment of career, and the core objective and fundamental task of university employment guidance is to cultivate and transmit independent and entrepreneurial talent.

\section{ACKNOWLEDGMENT}

On the role of career planning in college students ' employment guidance (17SZ20) supported by the $\mathrm{Yu}$ Lin University.

\section{REFERENCES}

[1] Tang lin, Jiang Shunhao. A rational reflection on the reform of employment guidance mode in colleges [J].China's higher Education Research, 2004 (1).

[2] [the U.S.A] Greenhaus. Career management [M].Beijing: Tsinghua University Press, 2003. [3] Yang yong. Career guidance and employment skills [M]. Beijing: China Material Press, 2004.

[3] Miu ninglin. The characteristics and enlightenment of professional career education in foreign universities $[\mathrm{J}]$.The exploration and research of Vocational education, 2005 (3).

[4] [the U.S.A] Greenhaus. Career management [M].Beijing: Tsinghua University Press, 2003.

[5] Wang Xinwen. On vocational guidance and college students ' employment [J]. Journal of Heihe River, 2006 (9).

[6] Peng Guangcheng, He Qiling, Yu Zhije. Analysis and thinking on the current guidance model of university students employment [J]. Journal of Yangzhou University (Higher Education Research Edition), 2006 (5). 